\title{
REPERENCES
}

For a full bibliography the classic paper of Franceschetti, Valerio and Babel should be consulted. The following are papers which were consulted by myself, and used in the text.

BÊçHET.-Dermat. Wochenschr., Vol. CV, p. 1152, 1937.

- Bull. Soc. franc. Derm. Syph., Vol. XLVI, p. 674, 1939.

Dascalopoulos, N.-Ann. d'Ocul., Vol. CLXIX, p. 387, 1932.

FranceschetTi, A., Valerio, M. and Babel, J.-Arch. Ophthal., Vol. XXXV, p. $5,1946$.

Lipschütz, B.-Arch.f. Dermat. u. Syph., Vol. CXIV, p. 363, 1913.

Thomas, E. W. Prosser.-Brit. Med. Jl. January 4, 1947.

Touraine, A.-Presse Méd., Vol. XLIX(I), p. 571, 1941.

URBANEK, J.-Zeitschr. f. Augenheilk., Vol. LXIX, p. 174, 1929.

- Ibidem., Vol. LXXXIII, p. 357, 1934.

WEEKERS, L. and RegINSTER, H.-Bull. Soc. belge d'Optal., Vol. LXXVI, p. 31 1938.

- Arch. d'Ophtal., Vol. II, p. 687, 1938.

Weve, H.-Arch.f. Augenheilk., Vol. XCIII, p. 14, 1923.

Whitwell. G. P. B.-Brit. Jl. Dermat, and Syph., Vol. XLVI, p. 414, 1934.

\section{FURTHER EXPERIENCE WITH AMNIOTIC MEMBRANE GRAFTS IN CAUSTIC BURNS OF THE EYE*}

\author{
BY \\ Arnold Sorsby, Joan Haythorne \\ and HOWARD REED \\ LONDON
}

IN an earlier communication (Sorsby and Symons, 1946) attention was drawn to the value of amniotic membrane grafts in the treatment of caustic burns of the eye. In a series of 30 cases (the burn being produced by lime in 22 cases; by hydrochloric acid, sodium hydroxide, and ammonia in 2 cases each; and by liquid sulphur dioxide and lead in 1 case each) no corneal or conjunctiva sequelae were noted in 27 cases. In 28 eyes in which vision was known 26 showed vision of 6/9-6/5. A method of applying the graft was described and it was indicated that early grafting gives the best results. Generally speaking the eyes were found to be very nearly white in 3 to 5 days after grafting and they were usually normal by the end of a week.

\section{1.-A further series of 28 cases}

Table I sets out the distribution and the clinical details in a further series of 28 cases. These fall into three distinct groups :

- Received for publication, May 5, 1947. 
1. Lime Burns (21 cases).

(a) Severity.-The severity of the burns can be judged by the following data:

Conjunctiva :

$\begin{array}{llll}\text { Both upper and lower fornices burnt } & \ldots & \ldots & 3\end{array}$

$\begin{array}{llllll}\text { Lower fornix only } & \ldots & \ldots & \ldots & \ldots & 16\end{array}$

$\begin{array}{llllll}\text { Inner half of conjunctiva } & \ldots & \ldots & \ldots & \ldots & 1\end{array}$

Lower fornix and outer half of conjunctiva ... 1

Cornea :

Clear

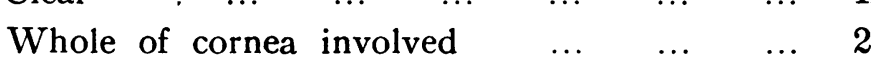

$\begin{array}{lllll}\text { Three quarters of cornea involved } & \ldots & \ldots & 3\end{array}$

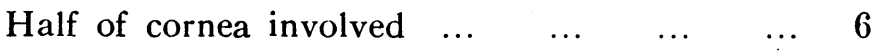

Lesser areas of cornea involved $\ldots \quad \ldots \quad \ldots \quad \ldots \quad 9$.

(b) Time of Grafting.-Grafts were invariably applied on the same day as the patient was seen. In 9 cases this corresponded to the day of the burn; in 10 cases it was a day after the injury was sustained. In one case the patient was not seen until 2 days after the injury, and in one more until after 4 days.

(c) Duration of Treatment. - Eight of these 21 cases were treated as out-patients. The time taken for the eye to become normal is shown in the following summary table:

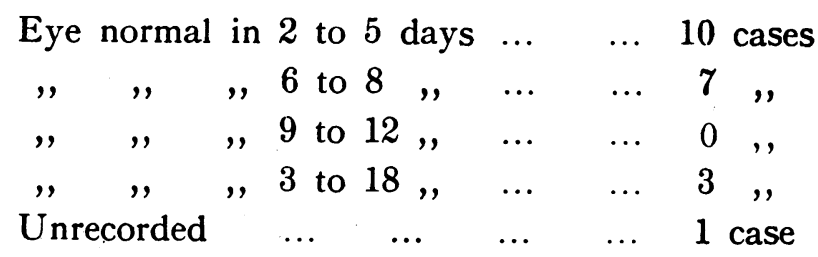

(d) End result. (1) Cornea.-In all but two cases the cornea was clear on discharge. In the two cases in which there was a corneal opacity a pre-existing corneal scar was present in one (No. 18), whilst delay in treatment appears to have been the responsible factor in the second one (No. 1), the one case in which the graft was carried out 4 days after the burn.

(2) Vision.-Apart from the one feature with a pre-existing corneal scar in whom vision was $6 / 24$, vision was good, or could 
be presumed good in the remaining cases. It was $6 / 6$ to $6 / 5$ in $12,6 / 9$ in 5 cases, and it was not recorded in 3 more, 2 of whom were illiterate children.

(e) Complications and sequelae.-Apart from the corneal opacity in case 1 already noted, a tendency to symblepharon was noted in 2 cases (Nos. 13 and 16). In each case this tendency was suppressed.by grafting; in case No. 13 the one graft used was adequate, whilst in No. 16 a further graft had to be inserted after 48 hours. In two more cases a second graft was found necessary : in case 9 , treated as an out-patient, the graft was found under the bandage when the eye was dressed after 48 hours ; in case 19 there was the unique experience of more staining of the conjunctiva being present on removing the bandage after 48 hours; in both these cases there was an uneventful recovery after a second graft.

\section{Sodium Hydroxide (5 cases).}

Three of the 5 burns produced by caustic soda can be dismissed briefly. The lower fornix was involved in 2 cases and the inner half of the conjunctiva in the third; the cornea was involved to the extent of $\frac{1}{4}, \frac{1}{2}$ and $\frac{3}{4}$ respectively. The grafts were all applied on the day of the burn. Two cases became normal in three days and one required 9 days. The cornea was clear in all cases and vision was $6 / 5$ in one case and $6 / 9$ with correction in the two others.

Considerably more severe injuries were noted in the two eyes of a man, aged 64 years. (Nos. 25 and 26.) When seen three hours after an explosion, in which his eyes were burned, both cornea were pearly opaque. Amniotic grafting was carried out on the same day, and subsequently twice more at intervals of 4 days, and finally once more 6 days later. A hypopyon developed in the right eye 20 days after the burn, when paracentesis and anterior chamber lavage were carried out. After prolonged treatment vision of the right eye was reduced to perception of light; a dead-white opacity of the cornea was present. In the left eye the lower two-thirds of the cornea is intensely opaque and vision is counting fingers at one metre.

3. Fireworks ( 2 cases).

Of the two injuries produced by fireworks one was a superficial conjunctival burn on the left side with three-quarters of the cornea staining. There was no conjunctival burn on the right side, but one-eighth of the cornea showed staining. Amniotic membrane grafting was carried out on the left eye on the day of injury with an excellent result. 


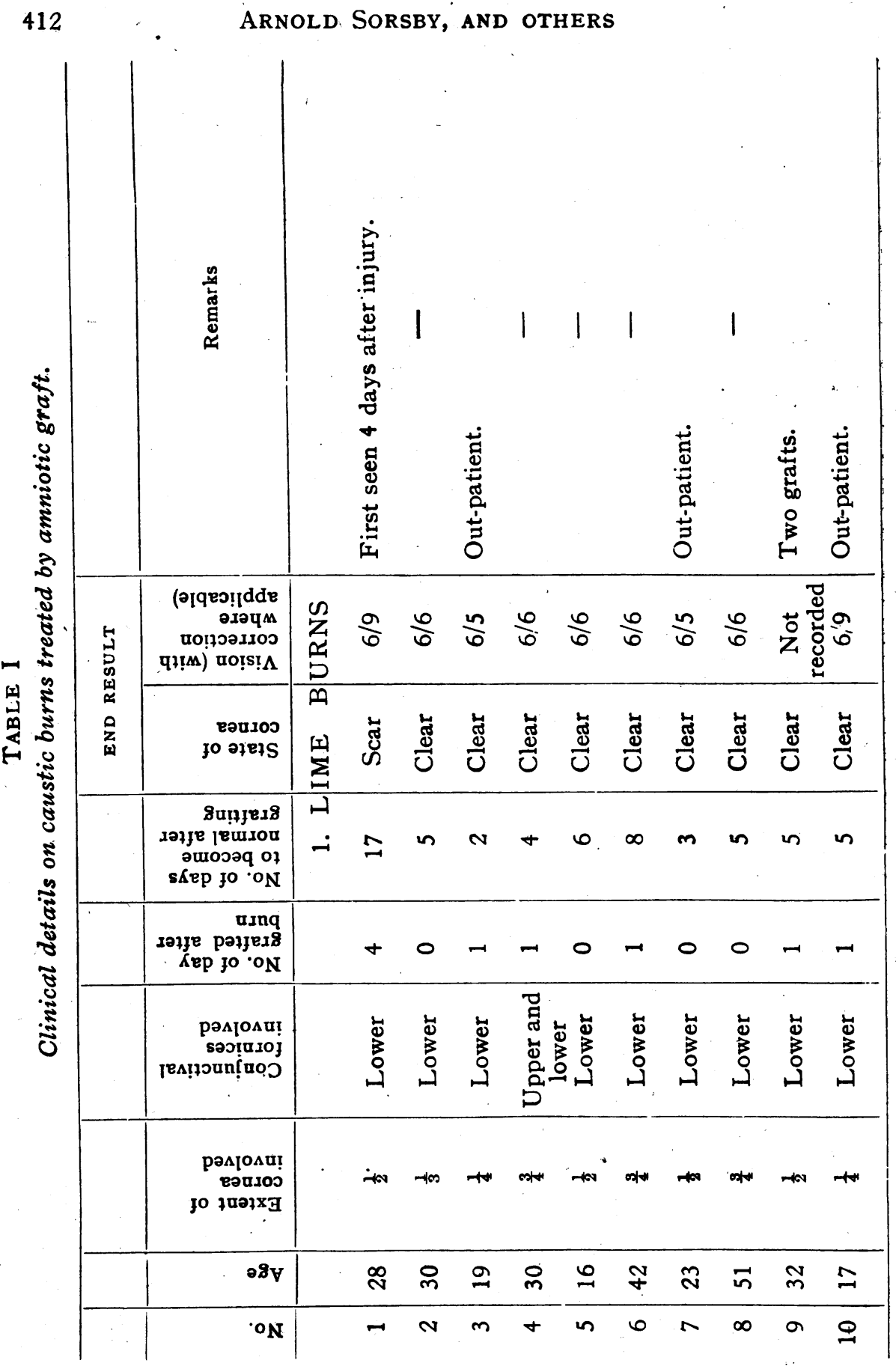

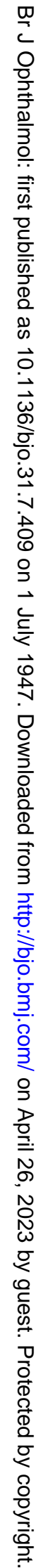


Amniotic Membrane Grafts

\begin{tabular}{|c|c|c|c|c|c|c|c|c|c|c|c|c|}
\hline 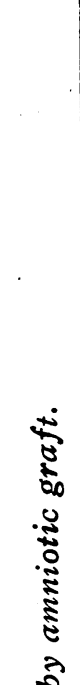 & & 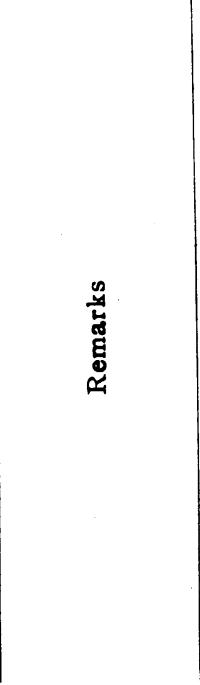 & 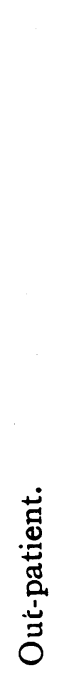 & & 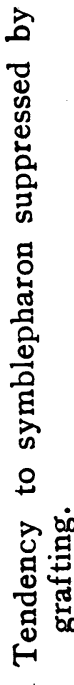 & 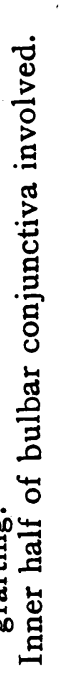 & 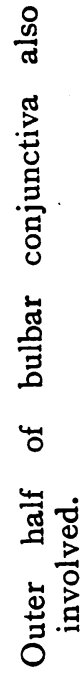 & 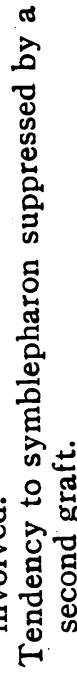 & ن & 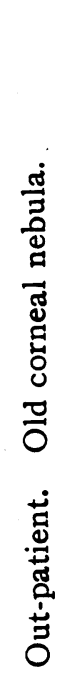 & 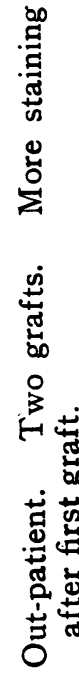 & $\begin{array}{l}0 \\
0 \\
0\end{array}$ \\
\hline $\begin{array}{c}0 \\
0 \\
0 \\
0 \\
0 \\
0 \\
0\end{array}$ & 点 & 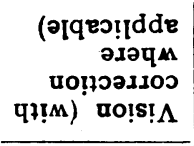 & $\frac{a}{b}$ & $\frac{a}{b}$ & $\frac{0}{6}$ & $\frac{n}{6}$ & 蔗葋 & 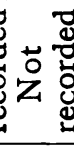 & $\frac{0}{6}$ & $\frac{\mathbf{J}}{\widehat{0}}$ & $\frac{0}{0}$ & $\frac{0}{6}$ \\
\hline 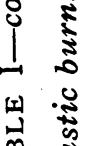 & 点 & 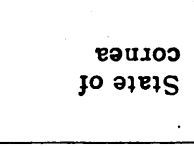 & $\frac{\vec{\Xi}}{\tilde{U}}$ & 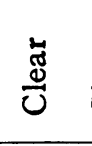 & $\frac{\vec{\Xi}}{0}$ & $\frac{\vec{\Xi}}{U}$ & $\frac{\vec{\Xi}}{\circlearrowright}$ & $\frac{\grave{\Xi}}{\circlearrowright}$ & $\stackrel{\widetilde{\Xi}}{0}$ & 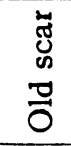 & $\frac{\text { ङ }}{0}$ & $\frac{\tilde{\Xi}}{\tilde{U}}$ \\
\hline $\begin{array}{l}\tilde{y} \\
0 \\
0 \\
0 \\
0 \\
0\end{array}$ & & 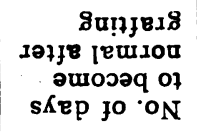 & 0 & 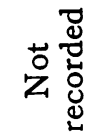 & & $m$ & $m$ & $N$ & 0 & $\stackrel{m}{-}$ & $\infty$ & $N$ \\
\hline 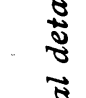 & & 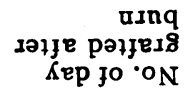 & 0 & 0 & $r$ & -1 & $\pi$ & 0 & - & $N$ & 0 & $\rightarrow$ \\
\hline 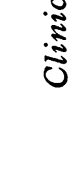 & & 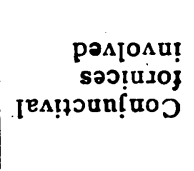 & \. & 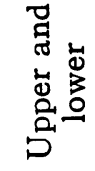 & 苟 & $\begin{array}{l}0 \\
\text { z }\end{array}$ & 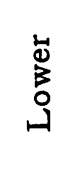 & 㐫 & 总 & 岕 & $\begin{array}{l}\overrightarrow{0} \\
3 \\
0 \\
0\end{array}$ & 岕 \\
\hline & & 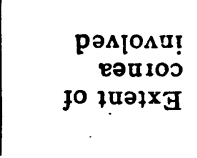 & $\rightarrow \infty$ & 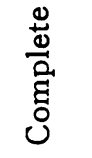 & ¿̊ & $+H$ & + & $+\pi$ & $-1 \infty$ & - & $H+H$ & $\rightarrow+\infty$ \\
\hline & & ว8ิ & $\tilde{m}$ & กี & $\underline{m}$ & $\stackrel{m}{m}$ & 0 & 0 & ○ & ఫ & $m$ & กี \\
\hline & & ${ }^{\circ} \mathbf{o}$ & $\exists$ & $\stackrel{N}{ }$ & $m$ & \pm & 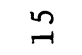 & $\stackrel{0}{ }$ & $\beth$ & $\stackrel{\infty}{\sim}$ & $\stackrel{g}{ }$ & 요 \\
\hline
\end{tabular}




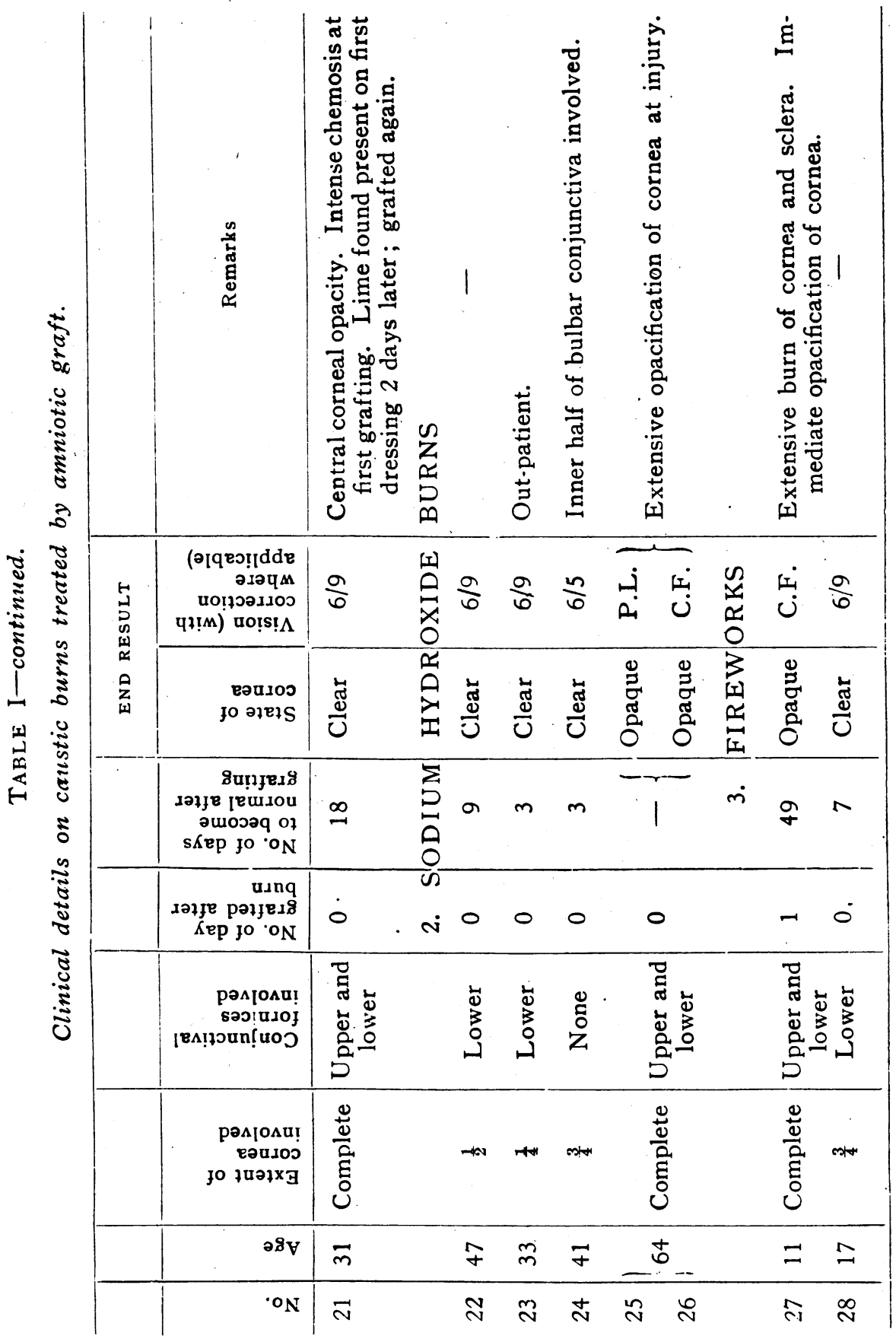


The second case was a severe burn involving the conjunctiva, episclera, sclera, and cornea of the right eye giving staining of the whole of the cornea with a total opacity. 'Though the final result was counting fingers in that eye, the clinical course during treatment and convalescence was not unsatisfactory. There was no marked tendency towards symblepharon, nor was there any worsening of the initial condition of the eye.

\section{2.--Discussion}

1. Significance of early grafting.-In the previous communication the difficulty in obtaining experimental control of the findings recorded was indicated. Nor could adequate clinical control be employed. Some approach to clinical control is, however, available by comparing the results obtained in the first series with those recorded in the present series. The 22 lime burns in the first series were submitted to grafting by amniotic membrane at variable times after the injury. At the beginning early grafting was exceptional, and it was only towards the end of the investigation that grafting on the day of the injury was undertaken. Classifying the data previously recorded the following summary table emerges.

\begin{tabular}{c|l}
$\begin{array}{l}\text { Number of day after burn } \\
\text { when grafting carried out. }\end{array}$ & $\begin{array}{l}\text { Duration in days of in-patient treatment } \\
\text { for each case respectively }\end{array}$ \\
\hline 0 & $\begin{array}{l}5,2,4, \text { and no in-patient treatment } \\
\text { in two cases }\end{array}$ \\
\hline 1 & 5 \\
2 & $10,8,7,12,10,6,2,5$ \\
3 & $17,15,11,27$ \\
4 & 9 \\
5 & 18 \\
10 & 21 \\
\hline
\end{tabular}

These results in themselves bear out the suggestion made in the earlier communication that early treatment is advisable. This suggestion is strengthened by the data in the following 
summary table on the present series extracted from Table I to show the time taken for the eye to recover its normal state in relation to the time when the graft was applied after the burn :

\begin{tabular}{c|l}
\hline $\begin{array}{l}\text { Number of day after burn } \\
\text { when grafting carried out. }\end{array}$ & $\begin{array}{c}\text { Number of days for eye to become normal } \\
\text { in each case respectively }\end{array}$ \\
\hline 0 & $5,6,3,5,6, ?, 7,8,18^{*}$ \\
1 & $2,4,8,5,5,5,3,3,6,7$ \\
2 & 13 \\
4 & 17 \\
\hline
\end{tabular}

" Case No. 21. Lime found in eye at first dressing of amniotic graft.

The fact that in both series late grafting involved prolonged treatment is indicative of the value of the procedure.

2. Mode of Action.-The experimental results previously reported suggested that human amniotic membrane was species specific in its action, and possibly tissue specific too, in so far as it reacted well with conjunctiva but not with skin. There is no support for species specificity or tissue specificity from experiments with tissue culture (Sorsby and Ungar, 1947). It would appear that amniotic membrane does not stimulate growth, but that it acts as a sort of internal splint for the proliferating tissue.

3. Mode of use.-The method previously described has stood the test of further use. Occasionally the procedure of inserting amniotic membrane has been modified in particular instances to cover defects in the conjunctiva not readily served by an implant into the fornix. In such cases partial covering of the cornea has sometimes to be used. In most cases such partial covering does not appear to act deleteriously in contrast to total covering of the cornea; moreover, the membrane generally tends to retract leaving the cornea fully exposed.

4. Limitations of amniotic membrane grafting.-Cases Nos. 25, 26 and 27 , which illustrate immediate and severe damage to the cornea, show the limitations of amniotic membrane grafting. It is necessary to distinguish clearly between immediate (and presumably irreversible) damage to the cornea and secondary involvement of the cornea from a persistent raw conjunctiva. 
Amniotic membrane grafting will have no effect on the first; it is invaluable as a preventative of the second type of corneal damage. A crude parallel is the cornea in ophthalmia neonatorum. The sulphonamides and penicillin have little effect on the damaged cornea; they are invaluable in preventing corneal ulceration and infection.

5. Method of preparing amniotic membrane grafts.-We are indebted to Mr. H. P. Morley of the Ligature Department, The London Hospital, for the following note on the mode of preparing amniotic membrane grafts of human origin. In his view the method of preparation is sufficiently simple to be possible in any well equipped pathological laboratory or dispensary.

(1) The placenta should be placed in normal saline immediately after delivery, the following process begun within twenty-four hours.

(2) Carefully separate the amnion from the chorion, commencing from the edge of the fringe up to the cord.

(3) Wash the amnion thoroughly in running water, then place in a saturated solution of common salt for twelve hours.

(4) Remove the amnion and immerse in a fresh saturated solution of common salt for twelve hours.

(5) Extend the amnion on black-backed plate glass and remove mucus and surface fat with gauze swabs.

(6) Wash thoroughly until the membrane is free from salt and immerse in distilled water from some ten to thirty minutes, frequently agitating the solution.

(7) Immerse the amnion in a 1 in 150 solution of potassium hydroxide (caustic potash) frequently agitating for at least one hour. No membrane being constant, the time factor is governed by the appearance of the membrane and experience.

(8) Extend the membrane on the plate glass and wash with distilled water, removing soaps formed.

(9) Pour hydroxide solution on the membrane and remove all remaining fat by manipulative massage with gauze swab. If necessary, further hydroxide baths and manipulative massage should be applied.

(10) Wash the membrane free of alkali.

(11) Test for fat by re-saponification.

(12). Immerse the membrane for twelve hours in distilled water, then stretch on wood frames measuring outside measurements $-6 \frac{1}{2}$ in. $\times 8 \frac{1}{2}$ in., divided into four sections. The $6 \frac{1}{2}$ in. $\times 8 \frac{1}{2}$ in. frames can be made of smooth, polished wood measuring $\frac{1}{2}$ in. $\times \frac{1}{2}$ in. and the wood dividing the frame into four, $\frac{1}{t}$ in. wide by $\frac{1}{2}$ in. deep.

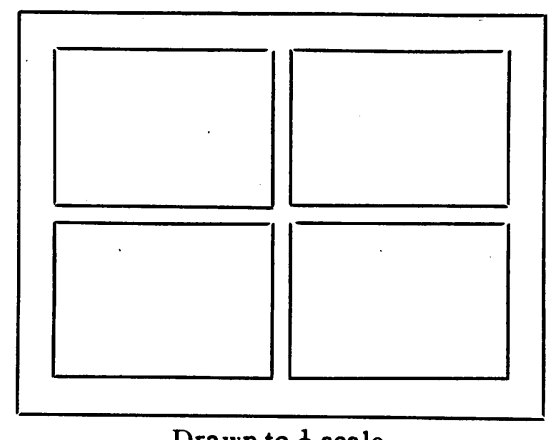

Drawn to $\frac{1}{4}$ scale.

The membrane will adhere naturally to the frames. 
(13) Allow to dry at ordinary room temperature, then remove from the frame and trim.

(14) Sterilisation is effected by dry heat at $150^{\circ} \mathrm{C}$. for one hour in open-mouthed cellophane envelopes.

\section{Summary}

(1) A further series of 28 cases of caustic burns of the eye treated by grafting with human amniotic membrane is recorded.

(2) There were 21 cases of lime burns. In 10 of these the eye was normal within 2 to 5 days, and in 7 more within 6 to 8 days. In all cases but one the cornea was clear at the. end of treatment. Vision of 6/9-6/5 was recorded in 17 cases, and could be presumed in three more. In two cases a tendency to symblepharon was controlled by grafting.

(3) There were 5 cases of burn due to sodium hydroxide, and 2 to fireworks. In 3 of these 7 eyes there was severe immediate corneal damage. This was uninfluenced by amniotic membrane grafting, though grafting affected favourably the course of these eyes.

(4) Taking the previous and the present series together it is shown that remarkably rapid response may be expected when grafting is applied on the same day, or within 24 hours after the injury; subsequently, recovery is slower.

(5) The mode of action of amniotic membrane grafting is not clear. It would appear that the amniotic membrane does not stimulate growth, but acts as a sort of internal splint for the proliferating tissue.

(6) The method of preparing amniotic membrane, as practised by $\mathrm{Mr}$. H. P. Morley, at the London Hospital, is described.

We are indebted to Sister Hollands and Sister Thorogood of the Ophthalmic Unit at Lambeth L.C.C. Hospital for their help with the treatment of these cases.

\section{REFERENCES}

MORLEY, H. P.-Personal communication.

Sorsby, A. and Symons, H. M. (1946).-Brit. Jl. Ophthal., Vol. XXX, p. 337.

SORSBY, A. and UNGAR, J. (1947).-Work in progress. 